\title{
New physiological classification of pains: current concept of neuropathic pain
}

\author{
Nova classificação fisiológica das dores: o atual conceito de dor neuropática
}

Carla Ceres Villas Miranda1, Lauro de Franco Seda Junior², Lia Rachel Chaves do Amaral Pelloso ${ }^{3}$

DOI 10.5935/1806-0013.20160037

\section{ABSTRACT}

BACKGROUND AND OBJECTIVES: Neuropathic pain is a complex entity and experts have tried to define it in a clearer and more objective way for its diagnosis to be more accurate, especially for non-specialists. Aiming at evaluating studies on the subject and their repercussion on medical practice, a systematic review was carried out from 2000 to 2016 on published studies about neuropathic pain, its definition and involved physiological aspects, using Pubmed, Cochrane and LILACS as databases.

CONTENTS: The new concept accepted by the International Association for the Study of Pain in 2011 considers neuropathic pain as "pain induced by injury or disease directly affecting the somatosensory system". So, "dysfunction", considered a vague term, was replaced by "disease", and "nervous system was replaced by "somatosensory system", to topographically delimit the disease. The new definition has created diagnoses based on clinical history and anatomic location, associated to evidential tests. Conditions such as diabetic polyneuropathy, post-herpetic neuropathy, compressive radiculopathy, other peripheral neuropathies and thalamic pain were well covered by new guidelines, however pains such as essential trigeminal neuralgia, fibromyalgia, complex regional pain syndrome type I, were excluded from the new definition.

CONCLUSION: Current concept is not ideal; it is limited and excludes major pain states and although the new classification has improved the understanding of neuropathic pain, further studies are needed on the subject.

Keywords: Concept, Neuropathic, Pain, Physiology.

\section{RESUMO}

JUSTIFICATIVA E OBJETIVOS: A dor neuropática é uma entidade complexa e os estudiosos tem procurado conceituá-la de modo mais claro e objetivo para que seu diagnóstico seja mais preciso principalmente para os não especialistas. Com a intençáo de avaliar os estudos realizados sobre o assunto e suas repercussóes na prática médica, foi realizada uma revisão sistemática do período de 2000 a 2016, sobre trabalhos publicados de dor neuropática, sua definiçấo e aspectos fisiológicos envolvidos, utilizando-se como base de dados Pubmed, Cochrane e LILACS.

CONTEÚDO: O novo conceito aceito pela Associaçáo Internacional para o Estudo da Dor em 2011 considera dor neuropática como "aquela decorrente de lesão ou doença que afeta diretamente o sistema somatossensitivo". Foram assim, substituídos os termos "disfunçáo", considerado vago, por "doença”, e "sistema nervoso" por "sistema somatossensitivo", para delimitar topograficamente a doença. A nova definiçâo criou sistemas de diagnósticos baseados na historia clínica e localização anatômica, associados a testes comprobatórios. Condiçôes como polineuropatia diabética, neuropatia pós-herpética, radiculopatias compressivas, outras neuropatias periféricas, dor talâmica, se en-

1. Hospital Municipal José de Carvalho Florence, Serviço de Neurocirurgia, Departamento de Dor Hospital Regional do Vale do Paraíba, São José dos Campos, SP, Brasil.

2. Hospital Beneficência Portuguesa de Bauru, Hospital e Maternidade São Lucas, Serviço de Neurocirurgia, Bauru, SP, Brasil.

3. Universidade Federal de Mato Grosso, Departamento de Cirurgia e Hospital Ortopédico, Área de Atuaçáo em Dor, Cuiabá, MT, Brasil.

Conflict of interests: none - Sponsoring sources: none.

\section{Correspondence to:}

Ladeira Săo José 110

12281-505 Caçapava, SP, Brasil

E-mail: ceresvillas@gmail.com

(C) Sociedade Brasileira para o Estudo da Dor caixaram bem nas novas diretrizes, porém estados de dor como na neuralgia essencial do trigêmeo, fibromialgia, síndrome da dor regional complexa tipo I, ficaram excluídas com a nova definição.

CONCLUSÁO: O conceito aceito atualmente não é ideal, é limitado, excluindo estados importantes de dor, e embora a nova classificaçáo tenha melhorado o entendimento da dor neuropática, se faz necessário a continuidade de estudos sobre o tema.

Descritores: Conceito, Dor, Fisiologia, Neuropática.

\section{INTRODUCTION}

Since its foundation in 1973, the International Association for the Study of Pain (IASP) has not spared efforts, through its taxonomy committee, to identify, define and classify different types of pain. Pain terminology and concept have as primary objective the development of criteria for diagnostic identification and formulation of treatment strategies in the clinical practice or in scientific studies. So, the development of new diagnostic means and the continuous renewal of treatment methods imply the eventual need to change concepts, giving a dynamic character to IASP's taxonomic classification.

So, when a term or definition moves away from its primary objective and becomes the target for criticism and divergence among authors, as it has been the case with Neuropathic Pain, IASP assigns a committee of specialists for its analysis and review. In more recent terms, neuropathic pain "is induced by injury or disease directly affecting the Somatosensory System" (IASP-2011). The old neuropathic pain (NP) concept was "pain induced by injury or dysfunction of the nervous system" and generated questions about "specific diagnosis and anatomic precision"'.

This publication was a landmark for the new definition of NP, because after years of discussions, they ended up creating tools for a more accurate diagnosis of this disease. Groups and societies, especially European, have decisively cooperated with guidelines to help non-specialist professionals diagnosing neuropathic pain. Technological advances have allowed for discoveries in genetics and immunology, of new markers which help understanding changes in pain phenotype. Even so, it is currently not clearly defined and accepted ${ }^{2}$.

\section{CONTENTS}

The desire along the years to understand and define neuropathic pain is because it is considered a different entity, a pain state, a syndrome, where highly potentiated nociceptive mechanisms generate extremely disagreeable symptoms, such as spontaneous pain (without noxious stimulation), tactile and dynamic allodynia, and hyperalgesia often refractory to existing therapies, being frustrating for physicians and patients ${ }^{3,4}$. Considered the pain that most deeply deteriorates quality of life with an estimated prevalence in general population of 3.3 to $8.2 \%$ and of up to $30 \%$ in other studies, it has become a public health problem, reason why studies about its etiopathogeny and pathophysiology are increasing worldwide.

Neuropathic pain has specific characteristics which differentiate it from other types of pain such ${ }^{5}: 1$. Pain and sensory symptoms which persist beyond the healing period. 2. Presence in variable degrees of sensory symptoms manifested by positive (hyperesthesia, paresthesia, disesthesia, allodynia) or negative (hypoesthesia, anesthesia) phenomena. 3. Presence in variable degrees of other neurologic motor and autonomic signs and symptoms manifested by positive and negative phenomena.

The definition proposed by IASP in 1994 for neuropathic pain as: "pain started or induced by primary injury or dysfunction of the nervous system"6 has remained official for several years, because it would partially differentiate it from physiologic nociceptive pain. This latter condition appears from the activation of afferent peripheral nociceptors, by actual or potential stimuli caused by tis- 
sue injury, whereas in neuropathic pain, pain is not necessarily induced by peripheral nervous terminations stimuli, implying the existence of a dysfunction mechanism, as supported by the definition of 1994. As time went by, several authors criticized current definition as vague or imprecise from the anatomic point of view and poorly specific in diagnostic terms ${ }^{7,8}$. Most generalists tend to classify as neuropathic any type of pain difficult to diagnose or treat. Bennett ${ }^{9}$ and Dworkin et al. ${ }^{10}$ have called the attention in 2003 to what they have defined as "diagnostic crisis", with regard to NP.

The term "dysfunction" of the old concept would not fit when a neural plasticity adaptation (peripheral and central sensitization phenomena) was considered a physiological response to major stimulation of the nociceptive system (ectopic discharges, changes in neuronal genome, changes in ion channels and endogenous inhibition of pain, activation of the immune system etc.) which would also be present in inflammatory pain and in chronic nociceptive pain ${ }^{3}$. So, its replacement by the term "disease" would help understanding that in NP there is a maladaptation of such plasticity, where central and peripheral sensitization mechanisms would be more exaggerated and persistently facilitated ${ }^{3}$

So, in these cases, what is seen is an area of hyperalgesia in the inflamed region, caused by temporary dysfunction resulting from integer nociceptive terminations sensitization by inflammatory mediators ${ }^{5,8}$. In addition, other diseases such as complex regional pain syndrome (CRDS) or fibromyalgia (FM), the pathophysiological mechanisms of which could not be explained just by a "dysfunction" were and are still controversial when classified as $\mathrm{NP}^{10}$. The term disease would be related to specific processes, such as channelopathies, autoimmune disorders and others, making pain a pathological state and not a physiological state of protecting against body injuries ${ }^{11}$.

The replacement of the term nervous system by somatosensory system in the new definition aimed at anatomically determining injuries and ruling out secondary pains of other parts of the nervous system, such as those caused by spasticity and stiffness mediated by the activation of muscle nociceptive afferents? However, it left to be desired because it has excluded pains located outside the somatosensory system and considered neuropathic, such as central neuropathic pain, pain by ischemic stroke (IS), MI, syringomyelia, syringobulbia, traumatic medullar pain etc., which would not be topographically located in the somatosensory system, e.g., affection of frontal lobe, cerebellum etc.

The best understanding of NP was then defined as disease directly affecting somatosensory nervous system perception ${ }^{1}$. So, in 2011, IASP by means of the Neuropathic Special Interest Group (NEUPSIG) has replaced the first definition which had lasted 17 years by current definition, launching a consensus on NP concept. The redefinition which has replaced these terms would match and remedy improprieties caused by previous concept ${ }^{12,13}$. According to current concept, which assumes the existence of a previous disease affecting and modifying the action of somatonsensory nervous system, it is possible to rank a series of conditions which meet mentioned characteristics, such as diabetic polyneuropathy, post-herpetic neuropathy, compressive radiculopathies, other forms of peripheral neuropathy, thalamic pain, and others ${ }^{5}$.

However, it is important to highlight that not all patients with specific disease acting on nociceptor sensory system will have pain as end product. This observation suggests that NP is present only in susceptible patients, probably by means of a preconceived genetic profile ${ }^{5}$. In other situations, is not pain that is developed as positive sensory manifestation. Many patients complain of an unpleasant not painful and spontaneous sensation, similar to smarting or burning (dysesthesia), while others refer pain in the site affected by commonly not painful stimuli (allodynia).

These symptoms, which may be isolated or associated to others, including pain itself, result from mechanisms similar to those determining $\mathrm{NP}^{5}$. So, faced to a same etiologic diagnosis, there might be a clinical heterogeneity of symptoms ${ }^{14}$. Clinical trial evidences have shown that depending on the combination of presented symptoms, it is possible to tailor by patient the specific pharmacologic treatment, thus optimizing results ${ }^{14,15}$. So, it is possible to develop treatment models for NP, starting from a perspective evaluating the multiplicity of symptoms, rather than pathophysiologic and etiologic mechanisms ${ }^{15}$.

This interest on pain biology was mainly due to the fact that some severe pain states are not related to existing tissue injury, as well as why chronicity is developed in some patients and not in others. It is possible that extrinsic (environmental, psychological) and intrinsic (genetic heritage) factors would be present in these questions. So, animal models were created to generate both nociceptive and neuropathic pain, where involved pathophysiological mechanisms could be studied. "However, animal studies are limited, because there is no report on their perception of pain, which limits the somatic, psychological and social focus, making difficult the concept and classification of types of pain"15.

Most published studies do not focus on precise classification of pain in its physiological character, exactly due to the difficulty of accurately proving mechanisms solely linked to one or other type of pain. These would be in a way present in more than one pain state, such as peripheral and central sensitization, being a physiologic response of neural plasticity. One maladaptation to this response would imply persistent pain states, including spontaneous pain generation (without nociceptive stimuli), being more common on chronic $\mathrm{NP}^{16}$. The need to classify pain in aspects different from temporal and etiologic, is due to the difficulty in obtaining satisfactory therapeutic results for chronic pain, especially neuropathic pain, since they would remain even with the resolution of their etiology. Better knowledge of these mechanisms would help the development of more effective therapies. Aiming at establishing certainty levels in NP diagnosis, Treede et al. ${ }^{1}$ have created a graduation system based on the clinical history pointing to the pre-existence of injury or disease of the somatosensory system and on physical evaluation pointing whether the area described as painful had reasonable neuroanatomic correspondence. In addition, both criteria were respectively reinforced by additional tests confirmation, thus creating four certainty levels for NP diagnosis (Table 1).

Table 1. Neuropathic pain evaluation system

Evaluation criteria by patient

1. Pain with reasonable anatomic distribution

2. History suggestive of relevant injury or disease affecting central or peripheral somatosensory system

3. Demonstration of distinct reasonable anatomic distribution in at least one confirmatory test

4. Demonstration of relevant injury or disease by at least one confirmatory test

NP would be classified as: permanent (criteria from 1 to 4 ), probable (criteria 1 and 2 with confirmation of 3 or 4 ) and possible NP (criteria 1 and 2 without confirmation of 3 or 4). Pain with reasonable anatomic distribution would topographically correspond to peripheral innervations of a territory or its representation in the central nervous system $(\mathrm{CNS})$. A history with temporal relation of neurological event and pain would confirm the suspicion. Neurological test with the presence of positive (allodynia, hyperalgesia, paresthesia etc.) and negative (different sensory deficits) signs, matching anatomic distribution. Adding to this laboratory and imaging tests which may identify and confirm the injury ${ }^{17}$.

These criteria logically help the concept and diagnosis of most neuropathic pains in known diseases, e.g., diabetic polyneuropathy, trigeminal neuralgia, post-herpetic neuralgia, post-ischemic stroke pain, post-spinal trauma etc., however they do not contemplate other entities known as NP states, such as CRPS type I, FM, interstitial cystitis etc., restricting their classification. These difficulties have led to a trend to call them dysfunctional pains.

Another term generating controversies and discussions, because the same mechanisms of physiological maladaptation to neural plasticity are observed in such pains, in NP and chronic nociceptive pain ${ }^{12}$. This graduation system created in 2007, although practical and with good acceptance, was too limited with regard to information related to types of presented symptoms. The French group for the study of NP has created in 2005 the DN4 questionnaire made up of 4 questions and 10 answer items (Table 2) $)^{15}$. The questionnaire is exclusively based on presented symptom, being the first two questions related to clinical history and patient's complaint about the painful area, and the two latter related to physical evaluation aiming at stimulating the affected region and the produced response.

Questionnaire score is obtained giving one point to each positive statement and zero to each negative statement. Cutoff value for NP diagnosis is four points. This diagnostic tool has shown to be very practical and easy to apply, being adopted by many as guidelines to identify NP. To reach a broader diagnosis, taking into consideration etiology, mechanisms and especially related symptoms, aiming at a more specific treatment, more complex diagnostic tools are used. In this sense, some rules for NP diagnosis are being used and constantly reviewed ${ }^{8,16}$.

The three more frequently used tools are the guideline of the German Neurologic Society (DGN), the guideline of European Federation of Neurologic Societies (EFNS) and the guideline of the NEUPSIG-IASP. Although there are 
differences in their structural design and preferences for one or other diagnostic tool, the validation of each one fundamentally depends on the methodology used for analysis.

Table 2. Douler Neuropatique en 4 questions - Neuropathic pain questionnaire

Your pain has the following characteristics:

Burning - yes no Painful cold - yes no Electric shock - yes no

Is there one or more of the following symptoms in the same area of your pain?

Tingling- yes no Pricking - yes no Numbness- yes no Itching- yes no

Is pain located in an area where physical evaluation may reveal one or more of the following characteristics?

Hypoesthesia to touch - yes no Hypoesthesia to needle pricking - yes no

Pain may be worsened in the painful area by:

$$
\text { Brushing - yes no }
$$

Score $0 / 10$

yes -1 point no-zero point

0 to $4-$ non-neuropathic pain 5 to $10-$ neuropathic pain

The intention to better redefine NP has led EFNS in 2009 to review existing guidelines, correlating them to new evidences published later evaluating their specificity for an accurate diagnosis. Most commonly used questionnaires were evaluated: MPQ (McGill Pain Questionnaire), LANSS (Leeds Assessment of Neurophatic Symptoms and Signs), NPQ (Neurophatic Pain Questionare), DN4 (Douler Neuropatique en 4 questions) and PAINDetect, in addition to quantitative sensitivity tests (tactile, thermal, vibrating).

They have observed that questionnaires failed in diagnosing 10 to $20 \%$ of patients with clinical diagnosis of NP and that sensitivity tests are valid and should be used concomitantly to improve diagnostic efficacy $y^{15,17,20}$. So, just with controlled, double-blind, randomized studies with homogenously trained professionals for clinical evaluation, it will be possible to prevent system vices which impair NP diagnosis. This opens a road for new ideas and studies about the pathophysiology of such pains.

\section{CONCLUSION}

NP is a challenge and undoubtedly the most studied subject under several aspects and also the most controversial for algologists of the clinic and academic world. Symptoms such as allodynia and hyperalgesia, common to other types of pain, made critical a neurological test showing changes according to the anatomically involved site, be it peripheral or central, and the help of laboratory and imaging tests for a possible, probable or final diagnosis. Even with studies of different methodologies, the multiplicity of questionnaires and evaluation tools, NP is still underdiagnosed and inadequately treated. The concept of NP has biases and requires continuity of studies on the subject. In the last decades, many publications with high methodological rigor have supplied relevant sci- entific support with regard to NP epidemiology, pathophysiological mechanisms, diagnosis and treatment.

So, many concepts used in the past need to be reviewed and adjusted to current times. In this sense, NP update and definition proposed by NEUPSIG-IASP in 2011 have provided focus in some aspects, such as the need for changes at anatomic level, however it has ignored important diseases currently considered neuropathic such as CRPS type I and Essential Trigeminal Neuralgia, as well as it has excluded and made more conflicting the classification of fibromyalgia. Anyway, such obstacles encourage the continuity of advances of studies and reorient new actions and clinical protocols.

\section{REFERENCES}

1. Treede RD, Jensen TS, Campbell JN, Cruccu G, Dostrovsky JO, Griffin JW, et al. Neuropathic pain: redefinition and a grading system for clinical and research purposes. Neurology. 2008;70(18):1630-5.

2. von Hehn CA, Baron R, Woolf CJ. Deconstructing the neurophatic pain phenotype to reveal neural mechanisms. Neuron. 2012;73(4):638-52.

3. Costigan M, Scholtz J, Woolf CJ. Neurophatic pain: a maladaptative response of the nervous system to damage. Annu Rev Neurosci. 2009:1-32.

4. Gilron I, Baron R, Jensen T. Neurophatic pain: principles of diagnosis and treatment. Mayo Clin Proc. 2015;90(4):532-45.

5. Backonja MM. Defining neuropathic pain. Anesth Analg. 2003;97(3):785-90.

6. Merskey H, Bogduk N. Classification of neuropathic pain. Seattle: IASP Press; 1994.

7. Cruccu G, Anand P, Attal N, Garcia-Larrea L, Haanpaa M, Jorum E, et al, EFENS guidelines on neuropathic pain assessment. Eur J Neurol. 2004;11(3):153-62.

8. Dworkin RH, Backonja MM, Rowbotham MC, Allen RR, Argoff CR, Bennett GJ, et al. Advances in neuropathic pain diagnosis, mechanisms and treatment recommendations. Arch Neurol. 2003;60(11):1524-34.

9. Bennett GJ. Neuropathic pain: a crisis of definition? Anesth Analg. 2003;97(3):619-20.

10. Dworkin RH, Backonja MM, Rowbotham MC, Allen RR, Argoff CR, Bennett GJ, et al. Advances in neuropathic pain diagnosis, mechanisms and treatment recommendations. Arch Neurol. 2003;60(11):1524-34.

11. Bennett GJ. Neuropathic pain: a crises of definition? Anesth Analg. 2003;97(3):619-20.

12. Bouhassira D, Attal N, Alchaar H, Bauneau F, Brochet B, Bruxelle J, et al. Comparison of pain syndromes associated with nervous or somatic lesions and development of a new neuropathic pain diagnostic questionnaire (DN4). Pain. 2005;114(1-2):29-36.

13. Haanpáã M, Attal N, Bachonja N, Baron R, Bennett M, Bouhassira D, et al. NeuPSIG guidelines on neurophatic pain assessment. Pain. 2011;152(1):14-27.

14. Üçeyler N, Sommer C. Neuropathic pain assessment - an overview of existing guidelines on discussion points for the future. Eur Neurol Rev. 2011;6(2):128-31.

15. Baron R, Tolle TR, Gockel U, Brosz ZM, Freynhagen R. A cross-sectional cohort survey in 2100 patients with painful diabetic neuropathy and postherpetic neuralgia: differences in demographic data and sensory symptoms. Pain. 2009;146(1-2):34-40.

16. Attal N, Fermanian C, Fermanian F, Lanteri-Minet M, Alchaar H, Bouhassira D. Neuropathic pain: are there distinct subtypes depending on the aetiology on anatomical lesion? Pain. 2008;138(2):343-53

17. Attal N, Fermanian C, Fermanian F, Lanteri-Minet M, Alchaar H, Bouhassira D. Neuropathic pain: are there distinct subtypes depending on the aetiology on anatomical lesion? Pain. 2008;138(2):343-53.

18. Motoc D, Turtoi NC, Vasca V, Vasca E, Schneider F. Physiology of pain - general mechanisms and individual aspects. Arad Med J. 2010;13(4):19-23.

19. Magrinelli F, Zanette G, Tamburin S. Neurophatic pain: diagnosis and treatment, Pract Neurol. 2013;13(5):292-307.

20. Timmerman H, Wilder-Smith O, von Well C, Wolf A, Vissers K. Detecting the neuropathic pain component in the clinical setting: a study protocol for validation of screening instruments for the presence of a neuropathic component. BMC Neurol. 2014;14:94. 